\title{
Social Acceptance of Dairy Farming: The Ambivalence Between the Two Faces of Modernity
}

\author{
Birgit K. Boogaard • Bettina B. Bock • \\ Simon J. Oosting • Johannes S. C. Wiskerke • \\ Akke J. van der Zijpp
}

Accepted: 12 April 2010/Published online: 28 April 2010

(C) The Author(s) 2010. This article is published with open access at Springerlink.com

\begin{abstract}
Society's relationship with modern animal farming is an ambivalent one: on the one hand there is rising criticism about modern animal farming; on the other hand people appreciate certain aspects of it, such as increased food safety and low food prices. This ambivalence reflects the two faces of modernity: the negative (exploitation of nature and loss of traditions) and the positive (progress, convenience, and efficiency). This article draws on a national survey carried out in the Netherlands that aimed at gaining a deeper understanding about the acceptance of modern dairy farming in Dutch society. People take two dimensions into account when evaluating different aspects of modern dairy farming: (1) the way living beings are used for production and (2) the way a dairy farm functions as a business. In both these dimensions people appeared to adopt cautious opinions: most people preferred relatively traditional and natural farms and were concerned about the use of nature and treatment of animals in modern production-although this did not imply an outright rejection of modern animal farming. The study also looked for (and sought to explain) differences of opinion between social groups. Besides sociodemographic factors such as age and gender, farming experience and valueorientation (such as socially minded and professional) appeared to be important variables. The values and convictions within modern society can help to explain why some people are greatly concerned about animal welfare while some show less concern. This diversity also helps to explain why general information campaigns are quite ineffective in allaying concerns about modern animal farming.
\end{abstract}

B. K. Boogaard $(\bowtie) \cdot$ B. B. Bock · J. S. C. Wiskerke

Rural Sociology Group, Wageningen University, Hollandseweg 1, 6706 KN Wageningen,

The Netherlands

e-mail: Birgit.boogaard@wur.nl

S. J. Oosting · A. J. van der Zijpp

Animal Production Systems, Wageningen University, P.O. Box 338, 6700 AH Wageningen,

The Netherlands 
Keywords Society $\cdot$ Citizens $\cdot$ Public $\cdot$ Values $\cdot$ Animal farming

\section{Introduction}

In urbanized societies, the spatial and social distance between citizens and farming is growing and many people have little experience with, or knowledge of, farming (Holloway 2004; Weber et al. 1995). At the same time, increasing numbers of people support organizations that stand up for (farm) animal rights (e.g., the "Party for the Animals" in the Netherlands or Animal Aid in the UK) and that challenge the acceptability of modern animal farming practices. Although many citizens share these views, it is not known how representative these organizations are of general public opinion.

Most studies about public opinions towards modern farming focus on a single issue, e.g., animal welfare (Kendall et al. 2006) or the rural area (Van Dam et al. 2002). Recent research has shown that people differ in their evaluation of various issues and aspects of modern-day farming (Boogaard et al. 2008), besides some issues are "complementary, while others are mutually exclusive" (Hall et al. 2004: 213). Therefore, a study about the public opinion of modern-day farming should take several issues simultaneously into account. In addition, these views and concerns differ between time and place, which makes it even more difficult to evaluate what the general public considers acceptable or unacceptable in modern (animal) farming and why (Hall et al. 2004). Equally, many people lack information or experience about farming and live far from the reality of present-day farming, although this does not mean that they are unwilling to or incapable of discussing the real dilemmas that exist in farming (Jones 1995; Macnaghten 2004). The present study aims at gaining a deeper understanding of the acceptance, or lack thereof, of modern dairy farming in Dutch society. It therefore addresses three research questions: (1) What image of contemporary dairy farming do citizens have and how does that match with their ideal, desired image of dairy farming? (2) What developments of modern dairy farming do citizens consider acceptable and unacceptable? (3) Which factors can explain differences between people's acceptance of modern dairy farming?

The paper is divided into six sections. After the introduction we elaborate on modern society's ambivalent relation with animal farming, summarized in what we define as the two faces of modernity. The third section explains the method used for data-collection - a national survey amongst Dutch citizens. In the fourth section we present the empirical findings, followed by the conclusions in section five. In the final section we discuss our findings in relation to current debates.

\section{Social Acceptance and the Two Faces of Modernity}

Society's relationship with modern animal farming is ambivalent: on the one hand there is increasing criticism about modern animal farming practices, such as the way farm animals are treated and used for production. On the other hand, people also 
appreciate certain aspects of modern animal farming, such as food quality and food safety (Boogaard et al. 2008) and low-cost products. Any attempt to gauge the acceptability of modern animal farming needs to bear this ambivalence in mind. Therefore we refer to a classical—but still relevant-debate about modernity.

Modernity is often characterized as a process driven by rational considerations and a firm belief in technological solutions (adapted from Scott 2006). Modernity has been welcomed as a positive development-associated with progress, convenience, (technological) innovation, efficiency, and prosperity. At the same time, however, the pursuit of modernity is also condemned because it frequently leads to a loss of traditions, customs, and values (Scott 2006). Modernity thus has both positive and negative faces that exist side by side. Both faces can be found in debates about modern animal farming, as we will discuss below.

\section{The Positive Face}

Modernity in farming refers to a process of specialization, concentration, and intensification (e.g., Tovey 2000). This process started after World War II (in the following named WW II) and was seen as an opportunity to produce more food, more efficiently, and at a lower price. The process was successful; farming systems became very efficient through the application of technology and automation and high levels of human control that rationalized and optimized production (Bos et al. 2003). Animal products became much more widely available and affordable. As recently as 2002 there still was observed "a continuing technological and structural development" in agriculture with a resultant "substantial rise in productivity" (Alrøe and Kristensen 2002: 4). This positive aspect of modernity is the implicit departure point of much scientific literature, particularly in the fields of animal sciences and agricultural engineering. For example, modernity is seen as a way of dealing with environmental problems by making more efficient use of input materials (Annevelink et al. 2003) and reducing emissions (e.g., Bos et al. 2003); it has the potential to provide social benefits by reducing labor through automation of processes, like milking (e.g., Oudshoorn et al. 2008) or address animal welfare issues by introducing "play" elements into the system (e.g., Bos et al. 2003). In summary, the positive face is characterized by a continuous search for optimal, efficient, and safe production of food based on a firm belief in technological innovations-reflecting values of progression, efficiency, and prosperity.

\section{The Negative Face}

The negative face of modernity is also expressed in criticisms about modern developments in agriculture, which go back a long time. In the 1970s, the introduction of milking machines into Dutch dairy farms met with strong resistance among (small) farmers who were forced to enlarge their farm or-if they were financially incapable of doing so-to quit farming (Bieleman 1998). But modernization not only raised economic and social issues; over recent years it has become clear that farming activities can damage the environment and nature (Macnaghten and Urry 1998). Moreover, the emphasis on increasing the productivity of animals is 
widely associated with negative effects, such as higher levels of disease outbreaks and other animal welfare issues (e.g., Franklin 1999; Macnaghten 2004). These aspects of modern farming threaten to undermine the widely-cherished notion of "the good life" in the countryside - the rural idyll and pastoral myth (Bell 2006; Cloke 2003, 2006; Short 1991, 2006). Modern animal farming is associated with industrialization and "factory farming systems where cows never feel grass beneath their feet" (Short 1991, p. 38) and where animals are "victims of a greedy, global economy" (Franklin 1999). Hence modern animal farming has many negative aspects, ranging from the loss of nature, depletion of resources, pollution of the environment, negative effects on animal welfare, loss of culture, and a decrease in the diversity of landscapes and food products. In summary, it can be described as a threat to natural and traditional values.

\section{Public Perception of Modern Farming}

After WWII the positive face of modernity dominated society's relationship with farming. Today by contrast the public seems more familiar with the negative aspects of modern animal farming systems. In response, farmers and agricultural organizations have initiated several attempts to highlight the achievements of modern farming (Holloway 2004). Recent studies (e.g., Boogaard et al. 2008) have shown that citizens appreciate certain aspects of modern animal farming, such as hygienic farm practices and technological innovations (e.g., automatic feeding devices). Thus while citizens seem more familiar with the negative face of modernity, they do not fully reject modern animal farming. Citizens are not for or against animal farming as such; they value certain aspects and criticize others simultaneously. Farmers and agricultural organizations often argue that the public is misinformed (Fraser 2001) and that a more accurate image of farming needs to be reconstituted by providing more information to the public (Holloway 2004). But people do not shape their opinion on the basis of knowledge and experiences alone; values and convictions also play an important role (Te Velde et al. 2002; Tuan 1974). In addition, we know from earlier studies (e.g., María 2006; Haartsen et al. 2003; Sharp and Tucker 2005) that socio-demographic variables such as gender, age, education, and income influence people's opinions about farming. For example, women are generally more concerned about animal welfare than men (e.g., María 2006) and elderly people have different expectations of the countryside than younger generations (e.g., Haartsen et al. 2003).

\section{Research Methods}

\section{A Three-Step Approach to Social Acceptance}

In line with the three research questions we approached people's acceptance of modern dairy farming in three steps (Fig. 1). In the first step, we sought to establish our respondents' images of dairy farming, because we expected that acceptance would be influenced by a combination of people's image of contemporary dairy 
farming and their desired image of dairy farming. In the second step we focused on precisely what people considered acceptable or unacceptable in dairy farming in relation to these aspects. In the third step we measured these differences in opinion and tried to explain them by peoples' frame of reference and their sociodemographic characteristics.

\section{Frame of Reference}

To develop our understanding of social acceptance for modern animal farming, we made use of the "frame of reference" concept and specifically focused on two of its main components: "knowledge and experiences" and "values and convictions" (Te Velde et al. 2002). We used three variables to express "knowledge and experiences": whether people grew up or lived in a rural area; if they had visited a farm in the past 2 years and if they had working experience in the agricultural sector. We also used three variables to capture people's convictions and values: their views about human-nature relationships and human-animal relationships and whether they held religious beliefs. Since values are not directly observable at the individual level; we classified values through the "WIN"-model ("Waardenoriëntaties In Nederland," "Value-orientations in the Netherlands") from the Dutch Institute for Public Opinion (NIPO). The WIN-model describes eight valueorientations in the Netherlands (Hessing-Couvret and Reuling 2002). Each valueorientation is derived from ranking different values. The WIN-model is based on well-known value studies (Oppenhuisen 2000; Rokeach 1973; Schwartz and Bilsky 1987) and consists of two axes (Fig. 2): the vertical axis expresses a continuum between focus on others and self-centeredness. As such, the more one moves upwards in the model, the more "self-centeredness" becomes "focus on others." The horizontal axis expresses a continuum between progress and conservatism, which illustrates a gradual shift from progression on the left to conservatism on the right. The WIN-model distinguishes between the following eight value-orientations (Table 1): socially minded, caring and faithful, conservative, hedonist, materialist, professional, broad-minded, and balanced (Fig. 2 and Table 1).

\section{Data-Collection: National Survey}

We conducted a national survey amongst Dutch citizens. The questionnaire was based on an earlier qualitative study in which citizens highlighted their concerns about dairy farming and the aspects they valued after having visited a pair of dairy farms (see Boogaard et al. 2008). The questionnaire consisted of six parts: (1) the image of contemporary dairy farming; (2) the image of the desired dairy farm; (3) the acceptability of modern developments in dairy farming; (4) human-animal and human-nature relations; (5) experience with farming; and (6) socio-demographic indicators. The six parts of the survey corresponded with the three-step approach (Fig. 1) in the following way: Parts I and II gave insights into contemporary and desired images (step 1). Part III related to what the respondents considered acceptable (step 2). For the final step-explaining differences in opinion-we used the answers from parts IV, V, and VI. 


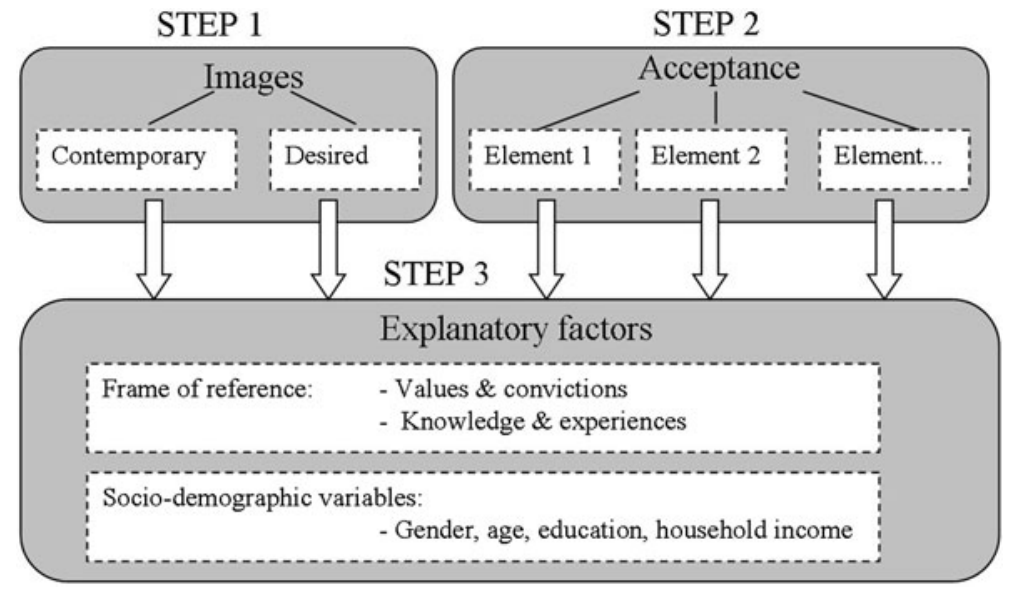

Fig. 1 Three-step approach to exploring social acceptance of dairy farming

Table 1 Key values within the eight value-orientations within the Dutch WIN-model (adapted from Hessing-Couvret and Reuling 2002)

\begin{tabular}{ll}
\hline $\begin{array}{l}\text { Value-orientation } \\
\text { Socially minded }\end{array}$ & $\begin{array}{l}\text { Most important values (based on Rokeach 1973) } \\
\text { Equality, inner harmony, a world of beauty }\end{array}$ \\
$\begin{array}{l}\text { Conservatives } \\
\text { Hedonists }\end{array}$ & F world of peace, equality, national security, salvation, helpful, forgiving, honest \\
Materialists & Pleasure, ambitious, cheerful, family security \\
& A comfortable life, an exciting life, mature love, ambitious, social recognition, \\
Professionals & Cappiness \\
Broad-minded & logical, an exciting life \\
Balanced & Freedom, imaginative, wisdom, broadminded, inner harmony, intellectual \\
\hline
\end{tabular}

To ensure that the respondents were generally representative of Dutch society at large rather than "non-representative pressure groups with specific agendas" (Hall et al. 2004: 224), respondents were selected from the NIPO-database (which includes 200,000 Dutch citizens). Respondents received a financial contribution for their participation to ensure that not only people with an agricultural interest would respond. The survey was programmed and placed online; only fully completed questionnaires were accepted. Within 2 weeks (between the 27th of February and the 7th of March 2007) 1,178 respondents of the 1,450 people approached had returned the questionnaire. This response rate (79\%) is good, even for the relatively experienced respondents within the NIPO-database. We checked the representativeness of the sample for gender, education, age, and urbanization against the standardized data for the Dutch population held by Statistics Netherlands ("Gouden standaard," "the golden standard" Hilhorst and Verhue 2007). Based on this 
comparison, the dataset may be considered as fairly representative, except for religious beliefs. ${ }^{1}$

Table 2 describes the reference grouping of respondents, which was derived from the 11 variables. Some response categories were not included within the analysis due to low response rates. This is the case for the response category "humans are subordinate to animals" (part of the variable "human-animal relations") and the response category "humans are subordinate to nature" (part of the variable "human-nature relations"). While asking the respondents which religion they adhered to, we only distinguished between those who defined themselves as "religious" and "non-religious." In a similar way, we measured the level of rurality of respondents' (former) residency on the basis of where people grew up and/or lived now. The combination of these two questions resulted in three possibilities, representing a decreasing level of rurality: (1) grown up, and now living, in a rural area, (2) grown up, or now living, in a rural area, (3) neither grown up, nor living, in a rural area.

\section{Method of Analysis}

The statistical analysis of the results consisted of three steps taken in line with the approach described above (Fig. 1). In the primary analysis we looked at respondents' contemporary image and desired image of dairy farming, conducting reliability analysis and calculating means and standard deviations. In the secondary analysis we analyzed respondents' acceptance of certain developments in dairy farming by conducting factor analysis and reliability analyses and by calculating means and standard deviations. Finally, in the third analysis we explained differences of opinion by means of a general linear model and correlations. We confirmed the analyses by cross validation by comparing a randomized $75 \%$, with the entire sample.

The primary analysis was based on parts I and II of the questionnaire. Part I focused on respondents' contemporary image of modern dairy farming via 17 propositions (Table 3). The respondents could indicate their level of support for these propositions on a scale from 1 (disagree completely) to 7 (agree completely). We calculated means, standard deviations and the overall-average of respondents' contemporary image of modern dairy farming (Cronbach alpha was 0.79). A high

\footnotetext{
1 All the respondents with a religious belief followed some form of Christianity: e.g., Catholic, Protestant or Baptist. Thus other religions such as Islam, Buddhism, or Hinduism were not represented. Since Dutch society contains increasing numbers of people following non-Christian religions (i.e., it is becoming a more "multi-cultural" society-see e.g., WRR 2007) this does represent a potential short-coming of the present study, especially as Muslims, for example, have quite different ideas about, and expectations of, the countryside (e.g., Jókövi 2000), food production and consumption than non-Muslims, i.e., the types of meat that they will eat and the ways in which they are slaughtered (Bonne and Verbeke 2008). This shortcoming is largely due to these groups being poorly represented in the NIPO-database, which consists of 200,000 Dutch citizens, all of whom have a Dutch cultural background.
} 


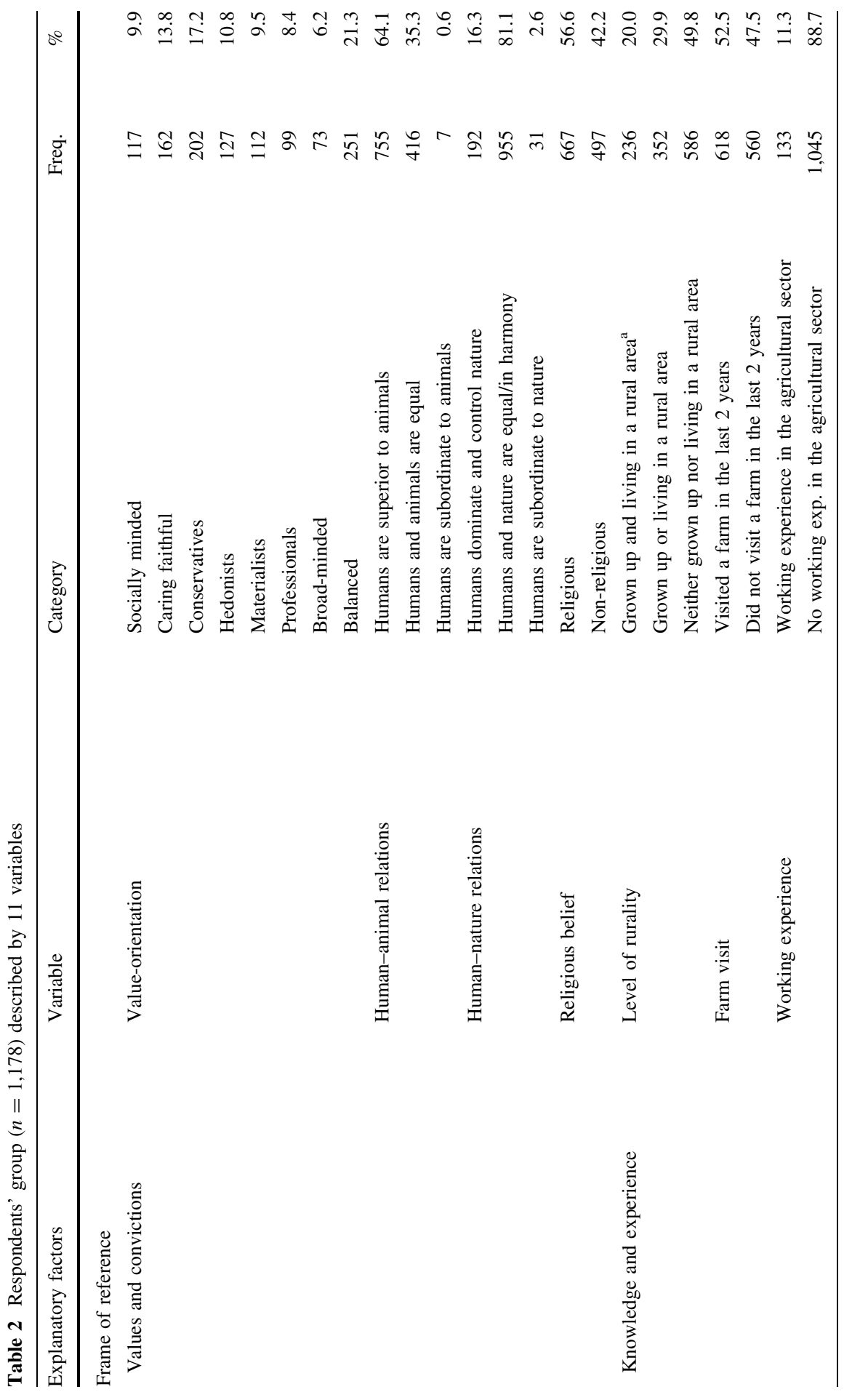




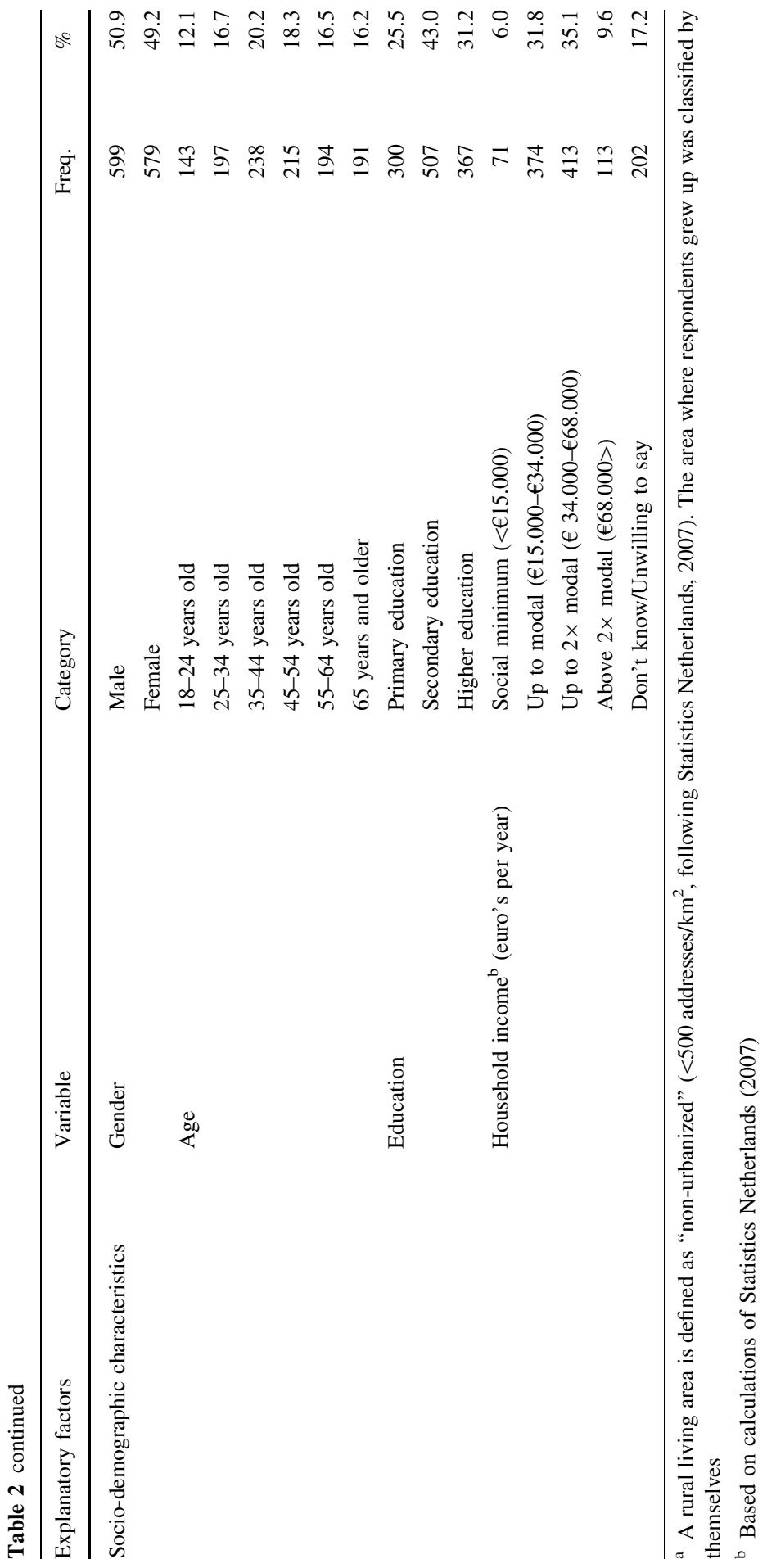




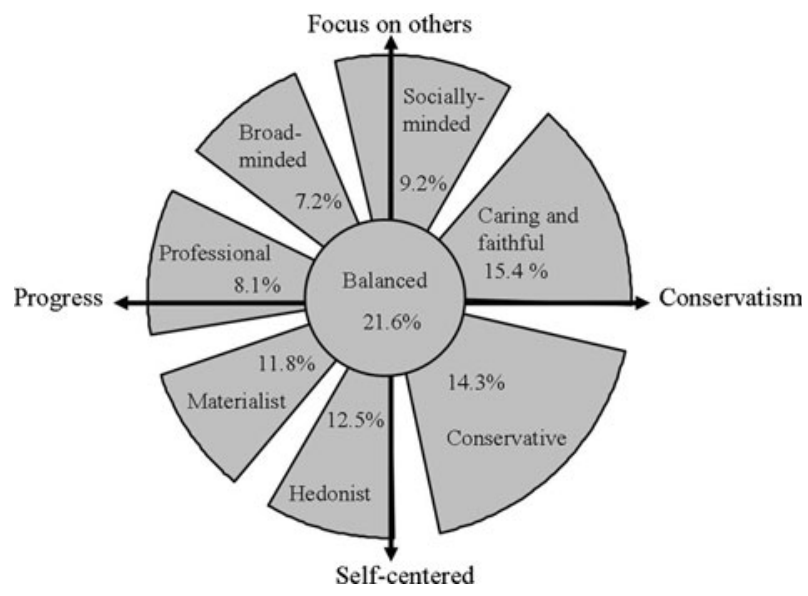

Fig. 2 Eight value-orientations in the Netherlands and their frequency of occurrence in 2007 (WINmodel) (Hessing-Couvret and Reuling 2002)

Table 3 Contemporary images of dairy farming (17 propositions)

\begin{tabular}{llll}
\hline Propositions & Mean $^{\mathrm{a}}$ & $\mathrm{SD}^{\mathrm{b}}$ & $n^{\mathrm{b}}$ \\
\hline 1. Dairy farming and nature can't co-exist & 2.47 & 1.29 & 1,172 \\
2. Being a farmer is simple & 2.39 & 1.22 & 1,165 \\
3. Dairy farmers pollute the environment & 3.26 & 1.43 & 1,137 \\
4. You need a good education to be a dairy farmer & 4.63 & 1.33 & 1,074 \\
5. Dairy farming has a one-sided, focused on maximum milk production & $\mathbf{4 . 8 4}$ & 1.46 & 1,150 \\
6. Dairy farmers spoil the landscape & 2.21 & 1.23 & 1,168 \\
7. Dutch dairy farming is a front runner in technological developments & $\mathbf{5 . 1 2}$ & 1.08 & 1,006 \\
8. Dutch dairy farming is maintained by subsidies & 4.27 & 1.37 & 1,035 \\
9. The income of dairy farmers is too low compared to their work load & 4.95 & 1.32 & 1,036 \\
10. Dairy cows have too little space to move around in modern sheds & 4.56 & 1.56 & 1,125 \\
11. Dairy farmers take good care of their animals & $\mathbf{5 . 4 7}$ & 1.24 & 1,164 \\
12. Dairy farms smell bad & 3.52 & 1.59 & 1,152 \\
13. The Dutch dairy sector does not mean much on the international market & 3.03 & 1.32 & 1,014 \\
14. Nobody wants to become a dairy farmer anymore & 4.09 & 1.36 & 1,107 \\
15. The Netherlands can do fine without dairy farmers & $\mathbf{1 . 9 0}$ & 1.06 & 1,169 \\
16. Life at a dairy farm is healthy for people & 4.85 & 1.21 & 1,126 \\
17. Dairy farmers do not keep up with the times & $\mathbf{2 . 5 9}$ & 1.17 & 1,136
\end{tabular}

\footnotetext{
${ }^{\text {a }}$ Minimum $1=$ completely disagree, Maximum $7=$ completely agree. Bold scores are discussed in the text

b $S D$ standard deviation, $n$ number of valid cases
}

overall score indicated that respondents were satisfied with contemporary dairy farming and a low score indicated dissatisfaction. Part II of the questionnaire focused on respondents' desired image of dairy farming. This part consisted of nine 
Table 4 Desired images of dairy farming: the positive and negative faces of modernity

\begin{tabular}{llrlrr}
\hline $\mathrm{Nr}$ & $\begin{array}{l}\text { Positive face of modernity } \\
\text { (convenience) }\end{array}$ & $\%$ & $\begin{array}{l}\text { Negative face of modernity } \\
\text { (threat to tradition and nature) }\end{array}$ & $\%$ & D.k. $^{\text {a }}$ \\
\hline 1 & Similar to other business companies & 11.8 & $\begin{array}{l}\text { Different from other business } \\
\text { companies }\end{array}$ & $\mathbf{8 5 . 8}$ & 2.4 \\
2 & Commercial company & 23.8 & Family farm & $\mathbf{6 9 . 1}$ & 7.1 \\
3 & More than 100 cows & 20.4 & Less than 100 cows & $\mathbf{6 6 . 5}$ & 13.1 \\
4 & Financial interests come first & 6.2 & Animals' interest comes first & $\mathbf{8 6 . 9}$ & 6.9 \\
5 & Cows are fed with feed from abroad & 1.7 & Cows are fed with Dutch feed & $\mathbf{8 4 . 9}$ & 13.4 \\
6 & Farmer is a manager & 2.6 & Farmer is a “craftsman" & $\mathbf{9 6 . 5}$ & 0.9 \\
7 & Clean and hygienic working practices & $\mathbf{7 2 . 3}$ & "Traditional” working practices & 23.1 & 4.6 \\
8 & Producing milk for the world market & $\mathbf{6 7 . 1}$ & Producing milk for Dutch market & 26.9 & 6.0 \\
9 & Mono-production of milk & 5.2 & Taking care of landscape and nature & $\mathbf{9 2 . 9}$ & 1.9 \\
\hline
\end{tabular}

a D.k. "Don't know" $(n=1,178)$

times double propositions, one of which presented "modernity as convenience," the positive face, and the other reflected values of tradition or nature-aspects threatened by modernity (Table 4). Respondents had to select which of the two they considered most desired or choose the opinion "I don't know."

The secondary analysis was based on part III of the questionnaire that focused on the acceptability of modern dairy farming. This part consisted of 16 "if/then" propositions, in which modern developments ("if") were juxtaposed with consequences for values relating to tradition and nature ("then"). For example, "If dairy farms become larger, then it is acceptable that the number of family farms decreases." Respondents could answer on a scale from 1 (disagree completely) to 7 (agree completely) or answer "don't know" (recoded as a missing value). Thus respondents who gave a score of 7 considered the given precondition completely acceptable, and those who gave a score of 1 considered the given development completely unacceptable. A score of 4 (neutral) lay half way between acceptability (less than 4) and unacceptability (more than 4). In a subsequent stage of the analysis we reduced the 16 "if/then"-propositions to four factors using an explanatory factor analysis. We gave equal weight to each proposition and recalculated the overall average per factor to measure the level of acceptability (Table 5).

In the third step of the analysis we analyzed the differences of opinions among respondents. We designed a General Linear Model (GLM) that included 11 independent variables (see Table 2) that might explain the main differences in opinions. We first ran the full model for the contemporary and desired images (Table 6) and then ran the full model for the four elements of dairy farming (Table 6). In addition, we performed post-hoc tests (either Gabriel's or GamesHowel's, depending on Levene's test) for significant main effects (at 0.05 level) and to gain further insights into differences between the groups. 
Table 5 Four factors (elements) of modern dairy farming

\begin{tabular}{|c|c|c|c|}
\hline Propositions per factor & Mean $^{\mathrm{a}}$ & $\mathrm{SD}^{\mathrm{b}}$ & $n$ \\
\hline First factor: Farming practices $($ Cronbach alpha $=0.67)$ & 3.24 & 1.04 & 1,170 \\
\hline $\begin{array}{l}\text { 1. If it is efficient and practical for a dairy farm, then it is acceptable that a dairy } \\
\text { farm has } 3,000 \text { dairy cows and a few milking robots. }\end{array}$ & 3.53 & 1.82 & 1,140 \\
\hline $\begin{array}{l}\text { 2. If it is efficient and practical for a dairy farm, then it is acceptable that } \\
\text { wooded banks are cut down. }\end{array}$ & 2.87 & 1.44 & 1,105 \\
\hline $\begin{array}{l}\text { 3. If it is efficient and practical for a dairy farm, then it is acceptable that a dairy } \\
\text { farmer does not have daily contact with the animals. }\end{array}$ & 2.72 & 1.46 & 1,166 \\
\hline $\begin{array}{l}\text { 4. If dairy farms become larger, then it is acceptable that the number of family } \\
\text { farms decreases. }\end{array}$ & 3.95 & 1.59 & 1,152 \\
\hline $\begin{array}{l}\text { 5. If it is necessary to keep a farm profitable, then it is acceptable that a dairy } \\
\text { farmer has to put economic interest above the animals' interests. }\end{array}$ & 3.13 & 1.52 & 1,159 \\
\hline Second factor: Farm animals $($ Cronbach alpha $=0.67)$ & 3.77 & 1.13 & 1,174 \\
\hline $\begin{array}{l}\text { 6. If it is efficient and practical for a dairy farm, then it is acceptable that a calf } \\
\text { grows up without a dam. }\end{array}$ & 3.04 & 1.65 & 1,163 \\
\hline $\begin{array}{l}\text { 7. If it is efficient and practical for a dairy farm, then it is acceptable that cows } \\
\text { are artificially inseminated (instead of being serviced by a bull) }\end{array}$ & 4.87 & 1.62 & 1,159 \\
\hline $\begin{array}{l}\text { 8. If the costs of a cow become higher than the profit, then it is acceptable that a } \\
\text { farmer brings the cow to the slaughterhouse. }\end{array}$ & 4.64 & 1.62 & 1,157 \\
\hline $\begin{array}{l}\text { 9. If it is financially necessary for the continuation of the farm, then it is } \\
\text { acceptable that cows are kept inside all year round. }\end{array}$ & 2.57 & 1.43 & 1,170 \\
\hline Third factor: Farm economics (Cronbach alpha $=0.58$ ) & 3.15 & 1.20 & 1,174 \\
\hline $\begin{array}{l}\text { 10. If it is too expensive to produce milk in the Netherlands, then it is acceptable } \\
\text { that dairy farms disappear (from the Netherlands). }\end{array}$ & 2.87 & 1.70 & 1,162 \\
\hline $\begin{array}{l}\text { 11. If farms can only exist with governmental subsidies, then it is acceptable } \\
\text { that dairy farmers receive subsidies (recoded value) }\end{array}$ & $\begin{array}{l}4.73 \\
(\mathbf{3} .27)\end{array}$ & 1.60 & 1,162 \\
\hline 12. If imported milk is cheaper than Dutch milk, then I will buy imported milk. & 3.31 & 1.62 & 1,157 \\
\hline Fourth factor: Consumer attitude (Cronbach alpha $=0.67)$ & 5.14 & 1.14 & 1,173 \\
\hline $\begin{array}{l}\text { 13. If Dutch milk is of better quality than imported milk, then I will pay more } \\
\text { for Dutch milk. }\end{array}$ & 5.44 & 1.22 & 1,170 \\
\hline 14. If dairy farmers take care of nature and landscape, then I will pay for it. & 4.85 & 1.39 & 1,165 \\
\hline
\end{tabular}

${ }^{\text {a }}$ Score $1=$ completely disagree, $7=$ completely agree. Unacceptable developments $($ mean $<4)$ are in bold

b $S D$ standard deviation, $n$ number of valid cases

\section{Empirical Findings}

\section{Step 1: Two Images}

The overall average result ${ }^{2}$ (4.82) implied that respondents were more pleased than displeased with contemporary dairy farming. Here we briefly discuss a few noteworthy results (shown in bold in Table 3) that highlight the two aspects of

\footnotetext{
${ }^{2}$ Several scores were transposed into "recoded values" so that all propositions were positively directed (on a scale from 1 to 7 ). The overall average was calculated using these "recoded values."
} 
Table 6 Significant main effects for six dependent variables (full model with 11 variables)

\begin{tabular}{|c|c|c|c|c|c|c|c|c|}
\hline \multirow[t]{3}{*}{ Independent variables $^{\mathrm{a}}$} & & \multirow[t]{3}{*}{$d f$} & \multicolumn{6}{|c|}{ Dependent variables } \\
\hline & & & \multicolumn{2}{|c|}{ Images $^{b}$} & \multicolumn{4}{|c|}{ Elements of dairy farming ${ }^{c}$} \\
\hline & & & Cont. & Des. & FP & FA & FE & $\mathrm{CA}$ \\
\hline \multicolumn{9}{|l|}{ Frame of reference } \\
\hline \multirow[t]{4}{*}{ Values and convictions } & Value-orientations & 7 & ns & $*$ & $* *$ & $* *$ & ns & $* *$ \\
\hline & Human-animal relation & 1 & ns & $* *$ & $* * *$ & $* * *$ & * & ns \\
\hline & Human-nature relation & 1 & ns & $*$ & $* * *$ & $* *$ & ns & $* *$ \\
\hline & Religious belief & 1 & $* *$ & ns & ns & ns & ns & ns \\
\hline \multirow[t]{3}{*}{ Knowledge and experience } & Level of rurality & 2 & $* * *$ & ns & ns & $* * *$ & ns & ns \\
\hline & Working experience & 1 & $* * *$ & ns & ns & $*$ & ns & ns \\
\hline & Farm visit & 1 & $* * *$ & ns & ns & $* * *$ & ns & $*$ \\
\hline \multirow[t]{4}{*}{ Socio-demographic } & Gender & 1 & ns & $* *$ & ns & ns & ns & ns \\
\hline & Age & 5 & $* * *$ & $* * *$ & ns & $* * *$ & ns & $*$ \\
\hline & Education & 2 & ns & ns & ns & ns & ns & ns \\
\hline & Household income & 4 & ns & * & ns & $\mathrm{ns}$ & $*$ & ns \\
\hline \multirow[t]{2}{*}{ Explained variance } & $R^{2}(\%)$ & & 13.3 & 10.2 & 10.6 & 18.3 & 5.6 & 7.1 \\
\hline & $R^{2}$-adjusted $(\%)$ & & 11.2 & 8.0 & 8.4 & 16.3 & 3.3 & 4.8 \\
\hline Number of respondents & $n$ & & 1,092 & 1,087 & 1,084 & 1,088 & 1,088 & 1,087 \\
\hline
\end{tabular}

modernity. In terms of modernity it is interesting to note that respondents disagreed with the proposition that dairy farmers do not keep up with the times (proposition $17, \mu=2.59$ ) and, in line with this, they generally agreed that "Dutch dairy farming is a frontrunner in technological developments" (proposition 7, $\mu=5.12$ ). At the same time, however, respondents confirmed that dairy farming has a one-sided focus on maximizing milk production (proposition 5, $\mu=4.84$ ) and strongly disagreed with the idea that "the Netherlands can do without dairy farmers" (proposition $15, \mu=1.90$ ). In addition, respondents quite strongly confirmed their views that "Farmers take good care of their animals" (proposition 11, $\mu=5.47$ ).

Based on the distribution in percentages (see the bold scores in Table 4), the following most desired characteristics of dairy farms emerged: they are different from other business companies; they should be family farms with less than 100 cows, where the animals' interest comes first and the cows are fed with Dutch feed; the farmer should be a craftsperson who works cleanly and hygienically and who produces milk for the world market while taking care of landscape and nature. This image reflects the continued appreciation for tradition and nature-such as family farming, the animals' interest, and the preservation of nature and the landscape, combined with aspects of modernity, such as clean and hygienic working practices and producing for export. This does not mean that traditional farming practices can not be clean and hygienic, but people identify and associate clean and hygienic 
farming practices as advantages of modern developments in dairy farming (Boogaard et al. 2008).

We measured the respondents' appreciation of modernity by using a "modernityindex." 3 The modernity index was the sum of seven items and had a scale running from 0 to 7; with higher scores indicating a greater desire for modernity within dairy farming and an average score of zero implying a desire for a completely natural and traditional dairy farm. Although the average score was not zero, it was still relatively low (2.15) and this suggests that respondents prefer a relatively traditional and natural type of dairy farm.

\section{Step 2: Four Elements of Dairy Farming}

Factor analysis revealed four factors. ${ }^{4}$ Each factor addressed a different aspect of modern dairy farming: farm practices, farm animals, farm economics, and consumer attitudes. The first two of these factors (farm practices and farm animals) relate to the modern-day treatment of animals and nature; in other words how living beings should be used in dairy production. The second two factors (farm economics and consumer attitudes) relate to how "businesslike" respondents thought a dairy farm should be (in other words how a dairy farm should function as a business company) and the extent to which consumers would be prepared to support things they consider desirable.

\section{The Use of Living Beings}

Questions about farm practices addressed an underlying dilemma between efficient and profitable production - the positive face of modernity-and a decline of farming traditions, such as reduced farmer-animal contact and a loss of hedgerows or wooded banks - the negative face of modernity. This factor consisted of five propositions, all of which attracted scores of less than 4 , thus all the developments towards modernization were considered unacceptable. Nevertheless, there were some differences between the five propositions. A decrease in farmer-animal contact was the least acceptable (proposition 3, $\mu=2.72$ ), followed by cutting down hedgerows and wooded banks (proposition $2, \mu=2.87$ ). Putting economic benefits above animals' interests was also-although less—unacceptable (proposition 5,

\footnotetext{
${ }^{3}$ We equally weighed the nine propositions and calculated the reliability on the basis of tetrachoric correlations. Two propositions (nr. 4 and 5) lowered the reliability of these results and we therefore omitted them from further analysis. Cronbach alpha for the seven remaining propositions was 0.78 .

${ }^{4}$ We used Varimax rotation. Two propositions (nr. 1 and 3) had low communalities and scored on more than one factor therefore we decided to remove them from further analysis. The final factor analysis resulted in four factors with an eigenvalue of $>1$ and explained $55 \%$ of the variance. The factor loadings were at least 0.45 and most of the criteria for factor analysis were met, that means: the Kaiser-MeyerOlkin Measure was 0.78 (should be $\geq 0.50$ ), Bartlett's Test of Sphericity was significant (Field 2008), the average communality was 0.55 (should be $\geq 0.60$ ) and Cronbach alpha's were around 0.67 (should be $\geq 0.70$ ) (Field 2008). Although our findings were slightly below the latter two criteria, we decided-after discussing with a statistician - to continue the analysis with these four factors, as they were the best we could get from this dataset. Moreover, validation with $75 \%$ randomly selected respondents resulted in the same four factors. We checked the four factors with reliability analyses.
} 
$\mu=3.13)$. Farms with a large number of dairy cows $(3,000)$ and a few milking robots were also considered unacceptable (proposition $1, \mu=3.53$ ). A decrease in the number of family farms attracted the least negative response, (proposition 4, $\mu=3.95$ ), very close to 4 , showing that respondents were ambivalent about the trade-offs between modernity and maintaining family farms. The overall average (3.24) implied that respondents found modernity in farm practices at the cost of farming traditions to be unacceptable and modern production techniques to be more negative than positive.

Questions about farm animals reflected an underlying dilemma between efficient and profitable production-the positive face of modernity-and reducing the naturalness of animals - the negative face of modernity. This factor was made up of four propositions. Artificial insemination and slaughter of unproductive dairy cows were considered acceptable (proposition $7, \mu=4.87$ and proposition $8, \mu=4.64$ ), whereas zero-grazing and the separation of calf and dam were considered unacceptable (proposition $9, \mu=2.57$ and proposition $6, \mu=3.04$ ). The overall average (3.77) implied that modernity in dairy farming at the cost of animals' naturalness was unacceptable, and modernity was again evaluated as being more negative than positive.

\section{Dairy Farming as a Business Company}

The questions about farm economics explored the underlying dilemma of cheap, possibly imported, and unsubsidized milk—-modernity as a convenience-against the disappearance of Dutch milk and dairy farms - modernity as a threat. The factor was made up of three propositions. Respondents were slightly in favor $(\mu=4.73)$ of government subsidies to maintain dairy farming in the Netherlands. They did not accept the disappearance of dairy farms from the Netherlands (proposition 10, $\mu=2.87$ ) or the purchase of cheap imported milk instead of Dutch milk (proposition 12, $\mu=3.31$ ). The overall average (3.15) implied that respondents considered modernity in farm economics to be unacceptable if it occurred at the cost of Dutch milk and Dutch dairy farms. However, this factor had a relatively low reliability (Cronbach alpha was 0.58), so care should be exercised with further analysis and interpretation of these results.

Questions about consumer attitudes explored the underlying dilemma of low product prices against payment for additional values, such as high product quality or maintenance of the landscape and nature. The factor was made up of two propositions, of which "paying more for Dutch milk of higher quality" attracted the most positive response (proposition 13, $\mu=5.44$ ). Respondents were also in support of "paying more to farmers who take care of nature and the landscape" (proposition 14, $\mu=4.85$ ). The overall average (5.14) implied quite a stated high level willingness among respondents to pay more for these additional values.

\section{Step 3: Explanatory Factors}

Below we describe the significant differences for each independent variable. In our analysis of "farm economics," we were confronted with some statistical 
restrictions ${ }^{5}$ that led us to conclude that the main effects described in the GLM (Table 6) were statistically not robust enough. Therefore we decided not to discuss this element in more detail. Within the four elements of dairy farming, a score of 4 represented a balance between what was considered acceptable $(>4)$ and unacceptable $(<4)$. Numbers in the following text refer to the corrected mean, e.g., "(2.51)" implies that a group of respondents gave a mean score of 2.51 (on a $1-7$ scale).

Contemporary images of farming were significantly influenced by their degree of rurality, working experience, and whether or not they had visited a farm in the past 2 years, which are all part of "knowledge and experiences." Age and holding religious beliefs were also significant factors (Table 6). The respondents who grew up and still live in a rural area were the most satisfied with modern dairy farming (5.04), those who either grew up or now live in a rural area scored slightly lower (4.94) whereas people who neither grew up, nor now lived in a rural area were the least content (4.85). People with working experience in the agricultural sector were more satisfied (5.05) with dairy farming than people with no agricultural working experience (4.83). People who had visited a farm in the last 2 years were also more positive (5.02) than those who had not recently visited a farm (4.86). Religious people were slightly more satisfied (5.00) with dairy farming than non-religious people (4.88). Finally, people over 65 years old were significantly more satisfied with contemporary dairy farming (5.12) than those between 18 and 44 years of age (4.80-4.85). In general, the more familiarity and contact people had with farming, the more satisfied they were with contemporary dairy farming.

The desired image of dairy farming was strongly influenced by value orientation, views about human-animal and human-nature relations, (all part of "values and convictions"), together with gender, age, and household income (Table 6). Professionals saw the traditional image of dairy farming as being the least desirable (2.36), compared to hedonists (2.10) and socially-minded respondents (1.75). Based on the WIN-model (Fig. 1 and Table 1) we can conclude that conservatives desired a more traditional and natural farm. Differences in beliefs about human-animal and human-nature relations showed that people who believed that these should be on an equal footing preferred a more traditional farm (2.02 and 2.03 respectively) than people who believed in human dominance (2.30 and 2.29 respectively). Women showed a stronger preference for more traditional dairy farms (2.03) than men (2.29). While all age groups showed a preference for more traditional farms, this preference was less pronounced among older age groups. People above 65 years of age gave an average score of 2.59 to this question, those between $45-54$ years gave 2.20, those between 35-44 years gave 1.86 and those between 25-35 years 1.85. Respondents with the lowest incomes (social minimum) expressed the strongest desire for traditional farms (1.84) and differed significantly from those with the higher incomes (those with twice the modal $=2.52$, those above the modal $=2.24)$.

\footnotetext{
5 The adjusted explained variance was very low (3\%, Table 6). Moreover, validation with $75 \%$ of the respondents resulted in different main effects than with the whole sample. In addition the reliability of this factor was quite low (alpha was 0.58 , should be around 0.70 ).
} 
Acceptance of farm practices was significantly influenced by respondents' value orientation and their views about human-animal and human-nature relations (Table 6). Respondents who believed in equality in human-animal or human-nature relations were less prepared to accept modern farm practices (3.10 and 3.11, respectively) than those who believed in human dominance (3.47 and 3.46, respectively). Respondents in the groups of faithful and caring (3.19) conservative (3.26) and the socially-minded (3.01) had significantly lower levels of acceptance of modern dairy farming than professionals (3.50) and materialists (3.48). These differences imply that people who value conservatism and who are focused on others consider modernity in farm practices less acceptable than those who value progress and/or who are self-centered (professionals and materialists).

Attitudes towards the treatment of farm animals were guided by a similar set of value orientations as attitudes towards farm practices. Other influential variables included respondents' level of rurality, their agricultural working experience and whether they had recently visited a farm (all related to knowledge and experiences). Age was another influential factor (Table 6). Professionals perceived modern developments to be acceptable, even if they occurred at the expense of animals' naturalness (4.21) whereas conservatives, hedonists, and socially minded people considered the same developments to be unacceptable (giving scores of 3.85, 3.89 and 3.76, respectively). Although the differences between these categories are relatively small, they are situated precisely across the balance point of what is and what is not considered acceptable (score 4). Thus, following the WIN-model we can conclude that people who cherish values of progress (professionals) consider modernity at the cost of animals' naturalness to be acceptable, whereas those who believe in values of conservatism take the opposite point of view.

Respondents who believed that human-animal or human-nature relations should be based upon equality considered modernity to result in unacceptable treatment of animals (3.67 and 3.83, respectively) whereas respondents who believed in human dominance in these relations considered the effects of modernity on animals' naturalness to be acceptable (4.21 and 4.05, respectively).

Respondents without experience of living in a rural area considered modernity in "farm animals" to be less acceptable (3.76) than those who currently lived in a rural area or had done so in the past (4.00 and 4.06, respectively). People lacking agricultural working experience considered modernity less acceptable than people with such experiences (3.81 vs. 4.07) - again a difference that bridged the divide between acceptability and unacceptability. People who had not visited a farm over the last 2 years considered modernity less acceptable (3.82) than people who had done so (4.06). Thus, the more experience people had with farming, the more they considered it acceptable to trade off modernity against animals' naturalness.

Socio-demographic variables, and particularly age, were a significant influence on responses to these questions. People older than 65 differed from the other agecategories in finding modernity in animal farming acceptable (4.37), and those between 25 and 34 years old considered the same developments the most unacceptable (3.68).

The level of acceptance in consumer attitudes was significantly influenced by value-orientation, views about human-nature relations, farm visits and age 
Table 7 Correlations between societal images and the level of acceptance of three elements

\begin{tabular}{|c|c|c|c|}
\hline \multirow[t]{2}{*}{ Images } & \multicolumn{3}{|c|}{ Elements of dairy farming } \\
\hline & Farm practices & Farm animals & Consumer attitudes \\
\hline Contemporary & $0.030(n=1,170)$ & $0.279 * *(n=1,174)$ & $0.103 * *(n=1,173)$ \\
\hline Desired & $0.421 * *(n=1,168)$ & $0.374 * *(n=1,172)$ & $-0.019(n=1,171)$ \\
\hline
\end{tabular}

** $P<0.01$ (Pearson 2-tailed)

(Table 6). Socially minded people were more willing than others to pay for additional services, such as milk quality or landscape (5.45). The largest difference was between socially-minded respondents and hedonists, implying that people who are focused on others express a greater willingness to pay than self-centered people. People who believed in equal relations between humanity and nature were also more willing to pay for added values (5.24) than people who believed in human dominance (4.96). People's knowledge and experiences also played a role, with people who had visited a farm in the past 2 years being more willing to pay extra (5.18) than those who had not visited a farm (5.02). People over 65 years of age were the most willing to pay extra (5.29) and people between 18 and 24 were the least willing to pay extra (4.98).

Finally, we wanted to gain further insights into the relationship between the images that respondents had of dairy farms and their acceptance of the issues surrounding dairy farming. Therefore, we calculated correlations between the two images and three elements of dairy farming, using Pearson's correlation co-efficients (Table 7). Views about farm practices correlated positively with those about the desired image of farming (0.421, Table 7); indicating that people who desired more traditional dairy farms were less accepting of modern farm practices. Views about farm animals correlated significantly with both contemporary and desired images of farming (values of 0.279 and 0.374 , respectively). The more content people were with contemporary farming, the more they accepted that modern treatment of farm animals would be at the cost of animals' naturalness. Finally, consumer attitudes correlated significantly with the contemporary image of farming (0.103, Table 7), showing that the more satisfied people were with contemporary farming, the more willing they said they were to pay for added values such as maintaining nature and landscapes.

\section{Summary of Empirical Findings}

The first step of the analysis gave answer to the first research question-What image of contemporary dairy farming do citizens have and how does that match with their ideal, desired image of dairy farming? This step showed that on average, respondents expressed a contentment with contemporary dairy farming (4.82 on 1-7 scale) although, when they could choose between different farm descriptions, they expressed a preference for a rather more traditional and natural type of farm (2.15 on the $0-7$ "modernity-index"). 
Exploratory factor analysis in second step revealed that people take two dimensions into account when evaluating different aspects of modern dairy farming: (1) the way living beings are used for production (as reflected in farm practices and the treatment of farm animals) and (2) the way a dairy farm functions as a business (as reflected in their evaluation of farm economics and their attitudes as consumers). This step gave answer to the second research question-What developments of modern dairy farming do citizens consider acceptable and unacceptable? The respondents showed the most concern over the negative effects of modernization on farm economics (3.15), farm practices (3.24), and the treatment of farm animals (3.77). As consumers they expressed a willingness to pay for added values. ${ }^{6}$

Finally, the third step answered the third research question-Which factors can explain differences between people's acceptance of modern dairy farming? On average, there were relatively few differences in opinions about modern dairy farming and acceptance of it among respondents. ${ }^{7}$ However, respondents' knowledge and experiences, their values and convictions and four socio-demographic variables, did make a difference. Respondents with experience or knowledge of farming (through farm visits, working experience, or residency in a rural area) were more satisfied with contemporary dairy farming and more accepting of modern ways of treating farm animals. People who had visited a farm in the past 2 years were also more willing to pay for added values than those who had not visited a farm.

Socially-minded respondents expressed stronger preferences for more traditional and natural dairy farms and were less accepting of modernity in farm practices and the treatment of farm animals than professionals. More generally the findings showed that conservative people expressed stronger preferences for traditional and natural dairy farms and were less accepting of modernity in farm practices and the treatment of farm animals than progressive people. People who believe in egalitarian relationships between humans and animals and in harmonious relationships between humans and nature also preferred more traditional and natural dairy farms and were less accepting of modernity in farm practices and the treatment of livestock. People who believed in harmonious relationships between humans and nature were also more willing to pay for additional values.

Of the socio-demographic variables, age was the most influential: respondents older than 65 were more satisfied with contemporary dairy farming, expressed less desire for traditional and natural dairy farms, were more accepting of modern methods of treating farm animals, and were more willing to pay for added values than younger respondents.

\footnotetext{
${ }^{6}$ Several studies have also shown that people are quite willing to pay for additional values (e.g., Bennett 1997). However, it is difficult to translate these findings to actual consumer behavior, because consumer behavior is influenced by many other factors than merely "willingness," and these questions reached beyond the aim of the present study.

7 These small differences might be the effect of the recalculated factor scores, because we calculated the average of the propositions and consequently the average factor score had a lower standard deviation than each proposition (see also Table 5). Therefore, the differences within the factor were smaller than the differences of the original propositions would have been.
} 


\section{Conclusions and Discussion}

This research aimed to gain insights into Dutch social opinions about the acceptability of different aspects of modern dairy farming. It also sought to make an inventory of and explain differences of opinion within the population. The study simultaneously investigated different aspects of dairy farming (Hall et al. 2004) revealing the complexities of people's opinions, which can be ambiguous and contradictory. Two dimensions of modern dairy farming were scrutinized: (1) the way living beings are used for production (where the elements included farm practices and the treatment of farm animals) and (2) the way a dairy farm functions as a business (where the elements included: farm economics and consumer attitudes). The first dimension reflects the dilemma between an instrumental and efficient use of land and animals as "production resources" and protecting animals, nature, and the environment. The second dimension reflects the dilemma between profitable self-supporting enterprises and farms that are supported by governmental subsidies and consumers' stated willingness to pay price premiums. In the following section we discuss the findings in relation to the ambivalence between the two faces of modernity, how social values influence views about the acceptability of modern day dairy farming and the implications of this in terms of "informing" the public.

\section{The Ambivalence Between the Two Faces of Modernity}

The study was conducted in the Netherlands - a highly urbanized country, with a highly productive and efficient agriculture and relatively little nature. Despite (or because of) this the vast majority of respondents $(81.1 \%$ ) considered it important that humans live in harmony with nature. Furthermore, more than a third $(35.3 \%)$ were convinced that humans and animals should be treated as equals, which may explain the recent success of the "Party for the Animals." Against this background one would expect quite low levels of acceptance of modern animal farming practices.

This expectation was partly confirmed: on average people found modern animal farming practices to be unacceptable and wanted to preserve and protect nature and animals. But condemnation of modern-day farming practices was moderate and was perhaps tempered by people's appreciation of certain modern achievements, as the following quotation from the study illustrates: ${ }^{8}$

I consider it important to defend the interests of animals, but this should not be done at the expense of everything else; although intuitively, I would like that to be possible. I understand that a farmer takes his cow to the slaughterhouse when she doesn't produce anymore. If it were down to me, the cow would have a relaxed old age. But I understand that this is not realistic in the Netherlands. (Dutch respondent)

\footnotetext{
${ }^{8}$ Respondents had the opportunity to make additional remarks at the end of the questionnaire and this quotation is one of these remarks.
} 
Overall, when comparing the negative and positive evaluations of the various aspects of modern dairy farming, the level of acceptance appears to be balanced and moderate. This does not mean, however, that people are not concerned about modernity in animal farming. The positive and negative evaluations of the different aspects of dairy farming do not completely balance each other out. The two faces of modernity often exist side by side and there is a certain ambivalence between the two.

This ambivalence is perhaps better understood by reverting to the idea of binary opposites. Humans have a tendency to categorize phenomena in opposite pairs (e.g., black and white, positive and negative) and try to mediate between them by searching for a third expression (Tuan 1974). In traffic signals, the color orange signifies neither "stop" nor "go", but "caution". Projected onto the topic of this study this example illustrates that people neither entirely accept modernity ("go"), nor do they entirely reject it ("stop"); instead their moderate level of acceptance can be interpreted as 'caution' towards modernity. The term "caution" captures the idea that people have a concerned or uneasy attitude, which may easily be aroused and mobilized at times of acute problems. Dairy farming has, to date, been a rather uncontested sector (Kjærnes and Lavik 2007). It is quite likely that this yellow sign could well turn to red if citizens were asked to evaluate more controversial animal farming systems, such as pig or poultry production systems. Earlier studies show that these systems meet rather stronger social opposition (e.g., Sharp and Tucker 2005; Kanis et al. 2003).

\section{The Importance of Values}

The study also shows that people's acceptance of modern-day dairy farming is related to what they find important in life - their fundamental value orientation. The growing divergence in values and convictions within modern-day society helps explain why some people are so concerned about animals' welfare and willing to support the campaigns of animal protection organizations, while others show little response.

The WIN-model distinguishes between eight value orientations expressed as continuums along two dimensions: between a focus on others and being selfcentered and between progress and conservatism (see Fig. 2). From this the model derives eight value-orientations, defined as: socially-minded, caring and faithful, conservative, hedonist, materialist, professional, broad-minded, and balanced. These distinctions proved to influence people's acceptance of modern dairy farming. Conservative people preferred a more traditional and natural farm and considered modernity less acceptable in the use of living beings (farm practices and farm animal treatment) than progressive people. Concern about the negative effects of modernization in animal farming is, therefore, related to a more generally conservative attitude. At a more detailed level we found the same difference between socially-minded people and those classified as professionals.

The Dutch Institute for Public Opinion (NIPO) describes socially-minded people as follows:

Socially-minded people are focused on harmony and stability. They are social and committed. They think about the consequences for their environment when making a decision. This segment mainly consists of relatively elderly 
people with quite a high educational level. They have interests in art, nature and politics. They don't have a materialistic mind, but are interested in fine, tasteful things. Their purchasing behavior is not at all influenced by new gadgets or technology.

(summarized and translated from Hessing-Couvret et al. 2003)

This description implies that socially-minded people are more concerned about nature and the environment (the negative face of modernity) than about the advantages of new technologies (the positive face). From this perspective, it is not surprising that these people consider modernity in animal farming least acceptable. This description also explains why socially-minded people express the most readiness to pay for additional values and green services. Although it cannot be assumed that they will act accordingly, in practice this is consistent with their generally mindful and responsible attitude.

According to NIPO social mindedness is often to be found among elderly people. In our study, however, elderly people (those over 65 years old) were more accepting of modernity in farm animal treatment and desired a less traditional and natural dairy farm than younger generations. This can probably be tracked back to idealized views of modernization that were widely held and promoted in the era when this generation grew up, and that for many may still be their natural point of reference. By contrast, younger generations grew up in an era where the negative effects of modernization became apparent and were widely debated, and modernity was no longer unanimously or unambiguously accepted as a force for good.

In contrast to socially-minded people, professionals have a preference for more modern and less traditional and natural dairy farms, and were the group that were most accepting of modern approaches in the use of living beings (farm practices and farm animals). They can be described as:

Ambitious and independent people, who are focused on their personal development and try to achieve an exciting and stimulating life. They are critical of, but open to, new ideas and different opinions. They are well informed about societal issues and politics. Professional households are most often two person households in the highest income bracket and their pattern of expenses clearly reflects this; they like luxury, tasteful, trendy products and are very accepting of and interested in technical gadgets. Other segments may define this group as "Young Urban Professionals."

(summarized and translated from Hessing-Couvret et al. 2003)

Thus, professionals are mainly young urban people who have faith in technological innovations and solutions, which probably explains their greater level of acceptance of modernity in the use of living beings.

Implications for "Informing" the Public

People with experience and knowledge of farming were the most content with contemporary dairy farming. In this sense knowledge and experience did positively 
affect people's image of modern farming. But this acceptance was also influenced by their value-orientation, especially when considering the treatment of farm animals. Thus, contrary to the expectations of agricultural organizations, generalized information campaigns will only have a very limited effect in influencing social opinions about, and acceptance of, modern farming systems. Concerns about modern animal farming will only be allayed when information is targeted at specific groups and addresses the more fundamental values that shape their concerns. The importance of values also indicates that people not only differ in their recognition of problems but also in how they will react to proposed solutions. The people who are most concerned about the negative impacts of modern dairy farming are unlikely to be convinced by solutions that rely upon technological innovations. On the contrary such approaches will most probably reinforce their concerns and mobilize their resistance.

Open Access This article is distributed under the terms of the Creative Commons Attribution Noncommercial License which permits any noncommercial use, distribution, and reproduction in any medium, provided the original author(s) and source are credited.

\section{References}

Alrøe, H. F., \& Kristensen, E. S. (2002). Towards a systemic research methodology in agriculture: Rethinking the role of values in science. Agriculture and Human Values, 19, 3-23.

Annevelink, E., Vink, A., Schouten, W. G. P., Smits, A. C., Hemming-Hoffmann, S., Lamaker, E. J. J., \& Groot Koerkamp, P. W. G. (2003). Food park, a case study of an integrated sustainable agro production park system designed with agro innovation framework. In Fourth European conference of the European Federation for information technology in agriculture, food and the environment (pp. 90-96).

Bell, D. (2006). Variations on the rural idyll. In P. J. Cloke \& T. Marsden (Eds.), Handbook of rural studies. London, UK: Sage.

Bennett, R. M. (1997). Farm animal welfare and food policy. Food Policy, 22, 281-288.

Bieleman, J. (1998). Boeren met machines. Het melkveehouderijbedrijf. In Techniek in Nederland in de twintigste eeuw [Farming with machines. The dairy farm. In Schot, J. W., \& de la Bruhèze, A. A. A. (Eds.), Technique in the Netherlands in the twentieth century] (pp. 99-126). Eindhoven: Stichting Historie der Techniek.

Bonne, K., \& Verbeke, W. (2008). Religious values informing halal meat production and the control and delivery of halal credence quality. Agriculture and Human Values, 25, 35-47.

Boogaard, B. K., Oosting, S. J., \& Bock, B. B. (2008). Defining sustainability as a socio-cultural concept: Citizen panels visiting dairy farms in the Netherlands. Livestock Science, 117, 24-33.

Bos, B., Groot Koerkamp, P. W. G., \& Groenestein, K. (2003). A novel design approach for livestock housing based on recursive control-with examples to reduce environmental pollution. Livestock Production Science, 84, 157-170.

Cloke, P. (2003). Country visions. Pearson: Harlow.

Cloke, P. (2006). Conceptualizing rurality. In P. J. Cloke \& T. Marsden (Eds.), Handbook of rural studies. London, UK: Sage.

Field, A. (2008). Discovering statistics using SPSS (2nd ed.). London: Sage.

Franklin, A. (1999). Animals and modern cultures: A sociology of human-animal relations in modernity. London: Sage.

Fraser, D. (2001). The "new perception" of animal agriculture: legless cows, featherless chickens and a need for genuine analysis. Journal of Animal Science, 79, 634-641.

Haartsen, T., Groote, P., \& Huigen, P. P. P. (2003). Measuring age differentials in representations of rurality in the Netherlands. Journal of Rural Studies, 19, 245-252.

Hall, C., McVittie, A., \& Moran, D. (2004). What does the public want from agriculture and the countryside? A review of evidence and methods. Journal of Rural Studies, 20, 211-225. 
Hessing-Couvret, E., \& Reuling, A. (2002). Het win-model ${ }^{T M}$. Waardensegmenten in Nederland [The WIN-model $^{T M}$. Value-orientations in the Netherlands]. Amsterdam: The Dutch Institute for Public Opinion.

Hessing-Couvret, E., Reuling, A., \& Mulder, S. (2003). Het WIN-model. Een segmentatie van de Nederlandse bevolking. [The WIN-model. A segmentation of the Dutch population]. Amsterdam: The Dutch Institute for Public Opinion.

Hilhorst, M., \& Verhue, D. (2007). Sociaal culturele duurzaamheid van melkveehouderijen. Veldwerkverantwoording [The socio-cultural sustainability of dairy farms. Field work justification]. Amsterdam: Bureau Veldkamp.

Holloway, L. (2004). Showing and telling farming: agricultural shows and re-imaging British agriculture. Journal of Rural Studies, 20, 319-330.

Jókövi, E. M. (2000). Recreatie van Turken, Marokkanen en Surinamers in Rotterdam en Amsterdam [Recreation of Turks, Moroccans and Surinamese in Rotterdam and Amsterdam]. Wageningen: Alterra.

Jones, O. (1995). Lay discourses of the rural: developments and implications for rural studies. Journal of Rural Studies, 11, 35-49.

Kanis, E., Groen, A. F., \& De Greef, K. H. (2003). Societal concerns about pork and pork production and their relationships to the production system. Journal of Agricultural and Environmental Ethics, 16, $137-162$.

Kendall, H. A., Lobao, L. M., \& Sharp, J. S. (2006). Public concern with animal well-being: Place, social structural location, and individual experience. Rural Sociology, 71(3), 399-428.

Kjærnes, U., \& Lavik, R. (2007). Farm animal welfare and food consumption practices: Results from surveys in seven countries. In U. Kjærnes, M. Miele, \& J. Roex (Eds.), Attitudes of consumers, retailers and producers to farm animal welfare (pp. 1-29). Wales: Cardiff University.

Macnaghten, P. (2004). Animals in their nature: A case study on public attitudes to animals, genetic modification and 'nature'. Sociology, 38, 533-551.

Macnaghten, P., \& Urry, J. (1998). Contested natures. London: Sage.

María, G. A. (2006). Public perceptions of farm animal welfare in Spain. Livestock Science, 103, 250256.

Oppenhuisen, J. (2000). Een schaap in de bus? Een onderzoek naar waarden van de Nederlander. [A sheep in the bus? A research into the values of Dutch people]. University of Amsterdam.

Oudshoorn, F. W., Renes, R. J., \& Boer, I. J. M. (2008). Systems in organic dairy production. Journal of Agricultural and Environmental Ethics, 21, 205-228.

Rokeach, M. (1973). Nature of human values. New York: Free Press.

RR, W. (2007). Wetenschappelijke Raad voor Regeringsbeleid. Identificatie met Nederland. [Scientific Council for Government Policy. Identification with the Netherlands]. Amsterdam: Amsterdam University Press.

Schwartz, S. H., \& Bilsky, W. (1987). Toward a universal psychological structure of human values. Journal of Personality and Social Psychology, 53, 550-562.

Scott, J. (2006). Sociology: The key concepts. London: Routledge.

Sharp, J. S., \& Tucker, M. (2005). Awareness and concern about large-scale livestock and poultry: Results from a statewide survey of Ohioans. Rural Sociology, 70, 208-228.

Short, J. R. (1991). Imagined country: Environment, culture and society. London: Routledge.

Short, B. (2006). Idyllic ruralities. In P. J. Cloke \& T. Marsden (Eds.), Handbook of rural studies. London, UK: Sage.

Te Velde, H., Aarts, N., \& Van Woerkum, C. (2002). Dealing with ambivalence: Farmers' and consumers' perceptions of animal welfare in livestock breeding. Journal of Agricultural and Environmental Ethics, 15, 203-219.

Tovey, H. (2000). Milk and modernity: Dairying in contemporary Ireland. Research in Rural Sociology, $8,47-73$.

Tuan, Y. F. (1974). Topophilia: A study of environmental perception, attitudes, and values. Englewood Cliffs: Prentice Hall.

Van Dam, F., Heins, S., \& Elbersen, B. S. (2002). Lay discourses of the rural and stated and revealed preferences for rural living. Some evidence of the existence of a rural idyll in the Netherlands. Journal of Rural Studies, 18, 461-476.

Weber, G. M., Hoban, T. J., Kendall, P. A., \& Bull, L. S. (1995). Consumer concerns about modern technology in agriculture: Considerations for undergraduate and graduate teaching. Journal of Animal Science, 73, 2727-2732. 